\title{
Entre lo público y lo privado: empleadores y trabajadoras domésticas frente al Tribunal del Trabajo Doméstico de la ciudad de Buenos Aires
}

\author{
Inés Pérez y Santiago CANEvaro \\ Consejo Nacional de Investigaciones Científicas y Técnicas \\ Universidad Nacional de Mar del Plata (Argentina) \\ Facultad Latinoamericana de Ciencias Sociales (Argentina) \\ inesp18@yahoo.com - sancanevaro@gmail.com
}

Recibido: 18-05-2014

Aceptado: 07-01-2016

\begin{abstract}
Resumen
El servicio doméstico ocupa un lugar ambiguo entre los mundos público y privado. Desarrollado en el interior de los hogares de los empleadores, da lugar a relaciones en las que lo laboral y lo afectivo están imbricados. Los juicios laborales entre empleadores y trabajadoras domésticas constituyen un escenario privilegiado para observar el solapamiento de estas dimensiones. Si las demandas de las trabajadoras frente a las instituciones de justicia sitúan esta relación en el mundo público, las respuestas de los empleadores muchas veces buscan resituarlas en el orden privado. Por otra parte, en algunos escenarios, las demandas de las trabajadoras son también expresadas en un lenguaje que remite a lo privado. En este artículo analizamos las lógicas de la conflictividad judicial establecidas en las estrategias de empleadores y trabajadoras frente al Tribunal del Trabajo Doméstico (TTD), un organismo creado en 1956 para atender los conflictos individuales que derivan de las relaciones de trabajo de este sector en la ciudad de Buenos Aires. Tomamos dos horizontes temporales caracterizados por cambios en la regulación del trabajo, en general, y del servicio doméstico, en particular: el de los primeros años de funcionamiento del TTD y el cambio de siglo.

Palabras clave: servicio doméstico; derechos laborales; afectividad; privado; público.

\section{Between the Public and the Private Worlds: Employers and Domestic Workers} before the Council of Domestic Workin Buenos Aires
\end{abstract}

\begin{abstract}
Domestic service occupies an ambiguous place between the public and private worlds. Performed inside the employers' homes, it gives place to relationships in which labor and affection are intertwined. The labor lawsuits between employers and domestic workers are a privileged stage to watch the overlap of these dimensions. While the demands of the workers before the institutions of justice put these relationships in the public world, the responses of employers often seek to resituate them in the private domain. Moreover, in some scenarios, the demands of the workers were also expressed in a language that refers to the private sphere. This article analyzes the logics of judicial conflicts in the strategies of employers and workers before the Council of Domestic Work (TTD), an institution created in 1956 to address individual disputes arising from employment relations in this sector in the city of Buenos Aires. We take two time horizons characterized by changes in labor regulation in general terms and, particularly, in domestic service: the early years of the TTD and the turn of the twentieth century.
\end{abstract}


Key words: domestic service; labor rights; affection; private; public.

\section{Referencia normalizada}

Pérez, I. y S. Canevaro (2016): "Entre lo public y lo privado: empleadores y trabajadoras domésticas frente al Tribunal de Trabajo Doméstico de la ciudad de Buenos Aires”, Política y Sociedad, 53 (1), pp. 169-186.

Sumario: Introducción. 1. Puntos de partida. 2. Trabajadoras y empleadores en los inicios del TTD. 3. Trabajadoras y empleadores frente al TTD en el cambio de siglo. 4. Consideraciones finales.

5. Bibliografía.

\section{Agradecimientos}

Agradecemos los comentarios de los evaluadores anónimos de Política y Sociedad, de los que la versión final de este texto se benefició enormemente.

\section{Introducción}

Durante la Modernidad, lo público y lo privado comenzaron a ser identificados como campos escindidos. Las metáforas que los teóricos contractualistas usaron para caracterizar el orden social moderno se asentaron en la imagen de un pacto social que hacía de los hombres ciudadanos iguales en el mundo público. Sin embargo, como ha mostrado Carole Pateman (1995), dicho pacto estaba precedido por otro de carácter sexual "que explica las claves del funcionamiento del ámbito privado y que permitió emancipar el espacio público y al nuevo modelo de ciudadano a costa del común sometimiento de las mujeres" (Nuño, 2008: 16). De esta manera, lo público, asociado a lo racional, a lo político, a la ciudadanía y a los derechos, se definió por oposición a lo privado, identificado, centralmente, con el mundo familiar formado por no-iguales.

También en el marco del pensamiento contractualista, el contrato de trabajo fue pensado como un contrato entre personas libres e iguales, cuyo objeto no era ya uno de los contratantes -como en las relaciones de esclavitud- sino su fuerza de trabajo (Pateman, 1995). A inicios del siglo XX, sin embargo, desde el campo del derecho comenzó a criticarse esta caracterización del contrato de trabajo, mostrando que se trataba, en realidad, de una relación desigual. A lo largo del siglo XX, la sanción de distintos derechos laborales buscó, si no igualar las posiciones de los contratantes, compensar en alguna medida esa desigualdad (para la Argentina, ver Stagnaro, 2012). En este sentido, los derechos laborales y la posibilidad de llevar a juicio a quien no los respetase contribuyeron a situar las relaciones de trabajo más claramente en el mundo público.

A pesar del reconocimiento de algunos de estos derechos para el servicio doméstico, esta ocupación continuó situada en un lugar ambiguo por su cercanía con el mundo familiar (para el caso de la Argentina, ver Pérez, 2015). El hecho de que el espacio de trabajo de la empleada fuera el hogar del empleador da lugar a una relación que excede lo 
estrictamente laboral y que muchas veces es definida como una relación cuasi-familiar. ${ }^{1}$ La "ambivalencia afectiva" (Goldstein, 2003) que la caracteriza ha tenido distintos efectos sobre la sanción de derechos laborales para las trabajadoras de este sector y, en términos más generales, sobre la percepción de lo justo en el marco de este empleo. Los juicios laborales entre empleadores y trabajadoras domésticas constituyen un escenario privilegiado para observar el solapamiento de estas dimensiones. Si las demandas de las trabajadoras frente a las instituciones de justicia sitúan esta relación en el mundo público, las respuestas de los empleadores muchas veces buscan resituarlas en el orden privado. Por otra parte, en algunos escenarios, las demandas de las trabajadoras son también expresadas en un lenguaje que remite a lo privado, en las que los reclamos no son sostenidos en la propia ley, sino en derechos nacidos de relaciones de afecto o cuasi familiares.

En este artículo analizamos las lógicas de la conflictividad judicial establecidas en las estrategias de empleadores y trabajadoras frente al Tribunal del Trabajo Doméstico (TTTD), un organismo creado en 1956 para atender los conflictos individuales que derivan de las relaciones de trabajo de este sector en la ciudad de Buenos Aires. Tomamos dos horizontes temporales caracterizados por cambios en la regulación del trabajo, en general, y del servicio doméstico, en particular.

En primer lugar, nos detenemos en los primeros años de funcionamiento del TTD (llamado inicialmente Consejo del Trabajo Doméstico), creado pocos meses después de la sanción del primer régimen legal para el sector en Argentina, en enero de $1956 .{ }^{2} \mathrm{Si}$ desde inicios del siglo XX se habían legislado distintas normas para la protección de los trabajadores (Suriano, 2007; Stagnaro, 2012), el servicio doméstico fue sistemáticamente excluido de ellas. ${ }^{3}$ Entre las justificaciones de dicha exclusión, se sostenía que en tanto formaba parte de la vida familiar, su regulación implicaba un avance del Estado sobre el mundo privado, lo que marcaba la necesidad de un estatuto

${ }^{1}$ El cruce entre dimensiones laborales y vínculos afectivos no es privativo del servicio doméstico, aunque adquiere en este caso algunas particularidades. Al trabajar en el hogar de sus empleadores realizando tareas que usualmente se asumen como responsabilidades de las mujeres de la casa, se produce un solapamiento con el trabajo doméstico no remunerado. En este sentido, es habitual que los empleadores se refieran a sus empleadas como "parte de la familia", aunque eso no implique una relación de igualdad con ellas. Para un análisis sobre las relaciones de las enfermeras con sus pacientes, ver Precarias a la Deriva, 2004; de los docentes con sus alumnos, ver Mac William, 1999; de las cuidadoras con quienes cuidan, ver Hondagneu-Sotelo y Ávila (1997).

${ }^{2}$ Si bien existen proyectos para la regulación legal de este sector desde comienzos de siglo, sólo el 1955 uno de ellos alcanzaría media sanción legislativa, proceso detenido por la llamada "Revolución Libertadora" (Tizziani, 2012). La desigualdad en relación a los derechos laborales de otros trabajadores, por otro lado, resulta común al observado en la región (Chaney y García Castro, 1989).

${ }^{3}$ Algunos derechos, como el salario anual complementario -sancionado en 1946 para el sector-, sin embargo, habían sido reconocidos a las trabajadoras domésticas previamente, aunque no en las primeras legislaciones sobre la materia. 
“especial" para este tipo de empleo. La sanción del decreto ley 326 de 1956 puede tomarse como indicio de un cambio en la sensibilidad social en torno de los límites entre el mundo familiar y el laboral. ${ }^{4}$ Este cambio tuvo lugar en un contexto en el que los derechos laborales habían sufrido un fuerte reconocimiento. Aunque tanto la sanción del decreto 326 como la creación del TTD fueron obra del gobierno de facto que derrocó a Juan Perón y que se opuso fuertemente a su política respecto de los sindicatos, estas medidas continuaron algunas de las lógicas instauradas en la década previa. Si el movimiento obrero había conseguido logros significativos desde principios del siglo $\mathrm{XX}$, solo con el peronismo muchos de los derechos laborales previamente reconocidos entrarían en vigor y serían extendidos a la mayoría de los trabajadores. Por otro lado, durante el gobierno peronista, las agencias estatales asumieron una posición explícita a favor de los trabajadores. Los primeros años del TTD estuvieron marcados por estas dinámicas, que influyeron fuertemente en los discursos tanto de las trabajadoras como de los empleadores.

En un segundo momento, nos detenemos en la década de 1990 e inicios de la del 2000, caracterizados por una creciente precarización de las condiciones laborales, un aumento significativo en las tasas de desempleo y por una fuerte desregulación del trabajo a partir de la flexibilización de muchos de los derechos laborales vigentes hasta entonces. La retracción de la intervención del Estado en la economía y, particularmente, en las relaciones laborales habla de una re-privatización del trabajo, que recién comenzaría a revertirse a partir de 2003. Si bien el servicio doméstico se desarrolló en su mayoría en el sector informal durante todo el siglo, lo que disminuía la posibilidad de las trabajadoras de hacer cumplir los derechos que legalmente les eran reconocidos (Valenzuela y Mora, 2009), la expansión del sector informal de la economía y del empleo no registrado en los años noventa disminuyeron la legitimidad del discurso de los derechos laborales, lo que se plasmó en las estrategias sostenidas por empleadores y trabajadoras frente al TTD. Por otra parte, a pesar de que desde el 2000, el Estado realizó distintos esfuerzos tendientes a mejorar las condiciones laborales en el sector (que se intensificaron a partir de 2006, culminando en la sanción de una nueva legislación en 2013), el servicio doméstico continuó entre las ocupaciones con mayores niveles de informalidad. ${ }^{5}$

${ }^{4}$ Ese cambio, sin embargo, no debiera exagerarse. El decreto 326/56 reconoció distintos derechos a las trabajadoras domésticas -como las vacaciones pagas, licencia por enfermedad, indemnización por despido y por preaviso, aportes previsionales, etc.-, aunque en grados menores a los reconocidos contemporáneamente a otros trabajadores. En buena medida, esta limitación responde a que, durante el período bajo análisis, el servicio doméstico sería considerado como una ocupación con una naturaleza particular, debido a la relación establecida en el ámbito de la intimidad del hogar.

${ }^{5}$ Desde el comienzo de la primera década del siglo XXI, sin embargo, el Estado argentino inició un conjunto de medidas tendientes a la registración laboral del sector y a la concientización de los derechos de las trabajadoras. En 2000, se sancionó un régimen especial para la seguridad social que amplió las posibilidades de acceso a prestaciones de salud y jubilatorias para las trabajadoras del sector. Sin embargo, las políticas más visibles y sostenidas hacia el sector 
En las próximas secciones, presentamos los puntos de partida de esta investigación, insertándola en el marco de los debates más recientes sobre el servicio doméstico y señalando los criterios metodológicos en que se fundó, para luego observar los modos en que lo público y lo privado fueron articulados en las estrategias de los empleadores $\mathrm{y}$ trabajadoras frente al TTD en los dos horizontes temporales propuestos.

\section{Puntos de partida}

En los últimos años los investigadores en Ciencias Sociales han mostrado un interés creciente por el servicio doméstico. En parte, este interés ha sido despertado por el incremento de la demanda de este tipo de trabajo en Norte América y Europa, suplida en buena medida gracias a la intensificación de las migraciones provenientes del Sur Global. El crecimiento de este tipo de empleo y el incremento de la proporción de migrantes entre las trabajadoras ha dado lugar a nuevas investigaciones sobre las "cadenas globales de cuidado" y las prácticas de las familias transnacionales (Salazar Parreñas, 2001; Lutz, 2008), así como sobre los vínculos entre las condiciones laborales y el estatus migratorio de las trabajadoras (Anderson, 2000; Gutiérrez Rodríguez, 2010).

Por otra parte, la movilización de las trabajadoras de hogar a nivel global también llamó la atención sobre este tipo de empleo. La aprobación del convenio C189 de la OIT en 2011 fue una de las conquistas de las trabajadoras que otorgó visibilidad a su lucha, tanto a nivel social como académico. Los investigadores han analizado los caminos, así como las estrategias y alianzas del movimiento de trabajadoras domésticas para lograr cambios en la legislación tendientes al reconocimiento de sus derechos (Blofield, 2012). También han discutido la efectividad de distintas políticas públicas para mejorar las condiciones laborales de este sector (Tomei, 2011; Bailly, Devetter Y Horn, 2013). Finalmente, las investigaciones han reconstruido la historia de las regulaciones de este

comenzaron unos años más tarde, en 2006, cuando se implementó un programa de regularización de las trabajadoras domésticas que desembocó en un relativo crecimiento del empleo registrado, programa que fue acompañado por una amplia campaña de difusión (Tizziani, 2012: 5). Más adelante, en marzo de 2010, la presidenta de la Nación, Cristina Fernández, presentó un proyecto de ley en torno a la modificación del Estatuto del Servicio Doméstico, que fue sancionado en 2013.Entre los elementos más importantes que incorpora dicha ley, podemos mencionar la reducción de la extensión de la jornada de trabajo para la modalidad "sin retiro" (externas), el derecho a percibir licencias por matrimonio, maternidad y asignaciones familiares, la obligación, para el empleador, de contratar un seguro por los riesgos del trabajo y el pago de horas extras. Asimismo, la ley se aplica a todas las trabajadoras domésticas, independientemente de la cantidad de horas trabajadas para un mismo empleador. También regula las horas de descanso para quienes trabajen "sin retiro", que tendrán un descanso de 35 horas continuadas, de sábado a lunes. Al ser incluida la licencia por maternidad, tal como lo establece la Ley de Contratos de Trabajo, y la estabilidad en el empleo, se equiparan las indemnizaciones que rigen para los trabajadores en general. Además, el personal de casas de familia queda incluido en el régimen de asignaciones familiares, del que estaba excluido. Las indemnizaciones por despido se equiparan con las del resto de los trabajadores -actualmente son muy inferiores-y se instituye la licencia por maternidad. 
tipo de trabajo en distintos escenarios nacionales e internacionales (Blackett, 2011; Boris and Fish, 2015).

En América Latina, el servicio doméstico representó la principal ocupación femenina a lo largo de todo el siglo XX. Sin embargo, estudios recientes aún hablan de la invisibilidad de este sector para las Ciencias Sociales (Lautier, 2003). A pesar de que el trabajo femenino ha sido una preocupación recurrente, en América Latina las investigaciones se concentraron en sectores industriales feminizados, como la industria textil y la de alimentos, y en otras ocupaciones en el área de servicios (docentes, telefonistas, secretarias, etc.). De la mano de la recuperación de las experiencias de las mujeres en el mundo del trabajo, la preocupación central de estos análisis era reconstruir los caminos por los que se habían delimitado "trabajos apropiados para su sexo", destacando el peso que en distintos casos adquirieron las alianzas entre las elites y los varones trabajadores en la exclusión de las mujeres de ciertas ocupaciones, y evidenciando el lugar de distintos agentes estatales en la domesticación de las mujeres (ver, por ejemplo, James y French, 1997; Rosenblatt, 2000; Hutchison, 2006; Lobato, 2007).En esta historia, las empleadas domésticas ocuparon un lugar más bien opaco. Recientemente, sin embargo, distintas investigaciones han arrojado una luz nueva sobre el servicio doméstico en la región (Hutchison, 2011; Pite, 2011; Milanich, 2011; Blofield, 2012; Canevaro, 2014; Pérez y Canevaro, 2015).

El presente artículo aborda una veta particular de este estudio, volviendo sobre el análisis de los usos de la ley de parte de empleadores y trabajadoras. El cuerpo principal de fuentes analizados para este artículo constó un total de 713 expedientes iniciados ante el TTD, distribuidos entre los períodos de 1956 y 1974 (621), y entre 1995 y 2013 (92). El relevamiento de los expedientes priorizó el análisis descriptivo y cualitativo en un esfuerzo por indagar la construcción de las narrativas de los actores. Una primera selección fue hecha al azar hasta que se encontró una matriz de regularidad en relación con el sentido de los discursos que aparecían en los expedientes. Un punto clave que emergió en la lectura pormenorizada de estas fuentes fueron las cuestiones relacionadas al carácter, la personalidad y los afectos existentes entre las partes. La aparición de tales aspectos constituyó uno de los ejes de comparación entre los períodos considerados.

Como una herramienta para analizar en los expedientes judiciales seguimos el trabajo pionero de Adriana Vianna (2010) para considerar "el lenguaje moral que atraviesa los 'derechos", no en la forma en que la legislación los consagra, sino observando el modo "en que son convertidos en asuntos de disputa y representación", entendiendo que "reparar en los dichos sacramentados en los autos es, entre otras cosas, mirar la conversión de legalidades en moralidades, en obligaciones, en gratitudes, en expectativas" (Vianna, 2010: 25). En este sentido, más que pensar en "la" moral en singular nos interesa pensar en moralidades, entendidas como un campo de enunciados sobre intenciones, actos y condiciones en las cuales esos actos fueron realizados (Herzfeld, 1981: 340-341); un campo capaz de ser descrito a partir de los dichos de los actores, del contexto en que tales dichos fueron producidos y de su poder en tanto argumentos, esto es, de dichos destinados a determinado fin. En particular, observamos cómo los derechos reivindicados por trabajadoras y empleadores ante el TTD articulan una moralidad fundada en la ley y en las relaciones laborales propias del mundo público, 
y otra que los hace depender de relaciones afectivas y cuasi-familiares características del mundo privado.

\section{Trabajadoras y empleadores en los inicios del TTD}

El TTD fue creado en 1956, bajo la órbita del Ministerio de Trabajo y Previsión de la Nación (Birgin, 2009). ${ }^{6}$ De acuerdo a un observador de la época, un año antes de la sanción del régimen laboral del Servicio Doméstico, en 1956, 350.000 personas se desempeñaban en esta ocupación (Fescina, 1956). Para 1964, se estima que el 20,7\% de las mujeres ocupadas en la Capital Federal se empleaba en el servicio doméstico. Además de ser la rama laboral más feminizada $(96,4 \%)$, concentraba a las mujeres de menores niveles de educación formal: el 94,3\% de las personas empleadas en el servicio doméstico habían asistido, como máximo, a la escuela primaria, mientras el $13,4 \%$ no había asistido a ninguna instancia de educación formal. ${ }^{7}$

El Consejo ofrecía un procedimiento, centrado en audiencias de conciliación. Sólo cuando aquéllas fracasaban, el proceso se abría a prueba. En ese marco, los elementos más importantes eran las declaraciones de testigos y la absolución de posiciones de las partes. En los expedientes es posible observar que la letra de la ley tenía un peso relativo. Tanto empleadas como empleadores solían no tener presentes sus derechos y obligaciones legales, situación que no era subsanada por las autoridades del Consejo, cuyo objetivo último era llegar a un acuerdo. Ahora bien, si los empleadores podían declarar no conocer la ley, solían tener asesoramiento letrado: las demandas de las trabajadoras eran usualmente contestadas por un abogado. Las trabajadoras, en cambio, muchas veces se presentaban solas y de manera espontánea ante las autoridades del Consejo, situación que solía sostenerse en las primeras audiencias y sólo cambiaba si el proceso se abría a prueba. En tanto el patrocinio letrado no era necesario para iniciar un expediente, las trabajadoras podían presentarse espontáneamente ante el TTD.

Por otro lado, durante los primeros años de funcionamiento del TTD, las voces de empleadores y empleadas estaban presentes con menos mediaciones que las que sobrevendrían en las décadas siguientes. Los representantes sindicales eran figuras importantes pero no tenían aún la relevancia que ganarían más adelante. Por poner un ejemplo, de los 293 expedientes que se han conservado de 1960, el sindicato (Sindicato Único de Personal Auxiliar de Casas Particulares) sólo participó en 40 (es decir, en el casi $14 \%$ de los casos). Otras figuras, como abogados y consejeros, otorgaban un espacio relativamente importante a la voz de los implicados. Entre otras cosas, los cuestionarios a partir de los que se interrogaba a los testigos en las audiencias de prueba eran elaborados por las partes y solían incluir descripciones detalladas de situaciones

\footnotetext{
${ }^{6}$ Su creación se enmarca en la de los Tribunales Laborales - que datan en Argentina de 1944aunque dependen de otro poder: si éstos dependen del Poder Judicial, aquél dependerá del Poder Ejecutivo y, en particular, del Ministerio de Trabajo y Seguridad Social (Stagnaro, 2012).

7 Estos datos fueron tomados de Encuestas de empleo y desempleo, Buenos Aires, julio de 1963 y abril de 1964, Instituto Nacional de Estadística y Censos, Buenos Aires, 1964.
} 
vividas como injustas. Incluso cuando la intervención letrada era evidente, como en las contestaciones de las demandas, abundaban los detalles de las historias personales. Las partes apelaban a distintas estructuras narrativas en las que los límites entre lo laboral y lo afectivo se volvían borrosos.

En buena parte de los casos, las empleadas habían trabajado menos de un año, pero hay casos de relaciones laborales mucho más extensas (de más de diez años) y mucho más cortas (de no más de unos días). Buena parte de las demandas eran iniciadas por empleadas que trabajaban como externas, aunque, en los años iniciales del funcionamiento del Consejo, en su mayoría, se trataba de empleadas internas. Es difícil establecer las tareas desarrolladas en el marco de la relación laboral puesto que, por lo general, no eran detalladas en las demandas: sólo se indicaba que se trataba de "empleadas para todo trabajo". Cuando se las desglosaba, éstas solían incluir "cocinar, lavar y planchar", "hacer la limpieza" y "ayudar a la esposa en los quehaceres domésticos del hogar". Las actividades también podían incluir el cuidado de niños o ancianos.

A diferencia de lo que ocurriría en las décadas posteriores, en este período los empleadores que se presentaban ante el Consejo solían reconocer la relación de trabajo. A pesar de ello, era frecuente que, en su respuesta, los empleadores presentaran la demanda de la ex empleada como una afrenta a una relación asentada en el afecto y la reciprocidad establecidos en el orden privado. La denuncia ante las autoridades de justicia, que emplazaba la relación en el ámbito público, encontraba como respuesta un intento de resituarla en el mundo privado. Por otro lado, en los casos en que no reconocían la relación de trabajo, la demandante podía ser presentada como una amiga de la familia o como alguien a quien se había dado auxilio en un momento de necesidad, lo que era favorecido por la cercanía entre las tareas desarrolladas por las trabajadoras y las que usualmente las mujeres realizaban en sus hogares sin una remuneración a cambio.

La mayoría de las trabajadoras declaraba haber sido despedida, elemento usualmente contestado por la parte empleadora, en tanto era determinante para el cobro de indemnización. En este sentido, las cualidades personales de la trabajadora se convertían en un elemento relevante. La ley abría esta posibilidad al establecer que "las injurias contra la seguridad, honor, intereses del empleador o su familia, vida deshonesta del empleado (...) faculta[ba]n al empleador para disolver el vínculo laboral sin obligación de indemnizar por preaviso y antigüedad." ${ }^{\prime 8}$ La descripción de un trato irrespetuoso de parte de las trabajadoras era una de las estrategias esgrimidas por los empleadores para justificar un eventual despido. Sin embargo, en muchos casos las consideraciones excedían el marco de la relación laboral para poner en evaluación la moral, y en particular la moral sexual, de la trabajadora.

En este sentido, es interesante recuperar un caso iniciado en 1964, en el que la empleadora justificaba el despido de la trabajadora por su conducta inmoral. Si bien el abogado de la empleadora sostenía que "en el aspecto laboral propiamente dicho, [su]

\footnotetext{
${ }^{8}$ Art. 6 del Decreto-ley 326/56.
} 
mandante toleró graves y serias deficiencias", lo que originó el despido fue que "en el aspecto personal... la conducta de la sirvienta no pudo merecer contemplaciones de ninguna especie". La trabajadora había mantenido una relación amorosa adúltera con el encargado del edificio en el que se encontraba el piso de la empleadora, quien había intercedido aconsejando a la empleadora "tratando de hacerla recapacitar y encauzarla por la senda del bien". Sin embargo, la trabajadora "tomó a mal sus palabras sabias, de hondo contenido moral, de persuasión para evitar situaciones reñidas con las enseñanzas y mandamientos de Dios, y nuestras leyes" y "en vez de agradecer estas reflexiones sanas, la sirvienta optó por agraviar e injuriar a su patrona y familiares, ante terceros". La moral sexual de la trabajadora se volvió relevante en tanto afectaba la imagen pública de la empleadora y su familia, quien se vio movida a aconsejar a su empleada por el "escándalo, ya de público conocimiento en el edificio". ${ }^{9}$ De igual manera, los agravios e injurias que recibió ante terceros fueron un elemento decisivo para terminar la relación laboral. La "vida deshonesta" de la trabajadora era considerada en tanto afectaba la respetabilidad del hogar de los empleadores.

La falta de adecuación a los parámetros de respetabilidad de género, podía, incluso, poner en duda la propia condición de trabajadora de la demandante. Así ocurrió, por ejemplo, en un expediente iniciado en 1959, en el que el demandado, para mostrar que la actora no había trabajado en su casa, señalaba que tenía una vida licenciosa, irreconciliable con la de una trabajadora honrada: se levantaba tarde, a las 10 de la mañana "y cada vez más tarde", salía y "hacía lo que quería", no estaba en casa del empleador en todo el día. Era, además, desagradecida, vengativa y mal hablada. Si había residido en casa del demandado, era, según sus dichos, porque había sido su huésped, alojada por "necesidad", y, al ser finalmente echada de la habitación que le había sido prestada, había insultado y amenazado a los dueños de casa con utilizar todos los medios para molestarlos. Aunque estos elementos no fueron relevantes en la sentencia del TTD (ni, más tarde, en la de la Cámara Laboral que resolvió en la apelación del demandado), resulta significativo que el demandado los presentara como única prueba de que la demandante no había trabajado para él.

Las demandas de las trabajadoras también destacaban aspectos que trascendían lo consagrado en la letra de la ley. Aunque no con la misma frecuencia que los empleadores, las trabajadoras también apelaban a un lenguaje de afecto y reciprocidad, que remitía al mundo privado, para fundar sus derechos. Por lo general, este tipo de lenguaje no aparecía en las demandas iniciales, sino cuando contestaban las respuestas de sus antiguos empleadores. En este sentido, este recurso solía seguir el intento de los empleadores de re-situar la demanda en una moralidad no regida por la ley sino por las normas propias del mundo privado. En sus estrategias frente al TTD, las trabajadoras también podían utilizar los estereotipos dominantes de género, ya fuera para identificarse como mujeres débiles a quienes sus empleadores habían explotado, para resaltar sus virtudes domésticas, o para poner en cuestión la estatura moral de sus antiguos empleadores. Así, por ejemplo, en un expediente iniciado en 1962, la

\footnotetext{
${ }^{9}$ Acta 48/1964.
} 
trabajadora sostenía que su antigua empleadora tenía una personalidad "violenta" que había generado la separación de su esposo del hogar conyugal. Este elemento contribuía a explicar el carácter intempestivo de su despido y, por otro lado, buscaba ganar la voluntad del funcionario interviniente del TTD.

Del mismo modo, en 1966, una trabajadora reclamaba sueldos, aguinaldos y vacaciones de toda la relación de trabajo, sosteniendo que su empleadora nunca, en los cinco años que había trabajado para ella, se los había pagado. En su defensa, la empleadora llamó a distintos testigos que, sin embargo, no hicieron referencia alguna a la ausencia del pago de salarios, sino que dieron fe de que ella "viv[ía] dedicada exclusivamente al cuidado de su hijo y a sus cátedras, llevando una vida completamente honesta". ${ }^{10}$ La demanda, en efecto, excedía la cuestión de los salarios y los derechos laborales, poniendo en el centro la moralidad de la empleadora, a la que se acusaba de estar fuera "durante todo el día, inclusive muchas noches porque [...] salía de paseo", razón por la que, se sostenía en la demanda, el hijo de la empleadora quería más a la trabajadora que a su propia madre. ${ }^{11} \mathrm{Si}$ la empleadora era caracterizada como una madre desapegada, con una moral sexual dudosa, la trabajadora, en cambio, era presentada como una "madre" sustituta. La empleadora, en su defensa, sostenía que debido a los eccemas que la trabajadora tenía en los brazos y manos, no le tenía permitido acercarse a su hijo y que, por esa misma razón, no podía hacer muchas otras tareas domésticas. En este caso, tanto empleadora como empleada organizaban sus estrategias frente al TTD como una competencia por el lugar de madre y ama de casa.

En las décadas centrales del siglo, la imagen del ama de casa ganó una nueva importancia en discursos políticos y expertos así como en los avisos publicitarios y los medios de comunicación (Milanesio, 2014; Pite, 2013). Aunque esta figura se identificaba con la clase media, su apropiación por parte de las mujeres de sectores trabajadores, y en particular por las empleadas domésticas, fue impulsada desde distintos espacios discursivos (Vázquez Lorda, 2010; Pite, 2011). Por otra parte, los derechos reconocidos a las mujeres en este período, como el derecho al sufragio, se fundamentaron en su vínculo con el hogar. Lo que resulta más relevante aún es que, previo a la sanción del Decreto-Ley 326, el único proyecto legislativo para reconocer derechos laborales al servicio doméstico que fue discutido en el Congreso Nacional y aprobado por la Cámara de Diputados -en un proceso interrumpido por el golpe militar de 1955- fundaba dicho reconocimiento en el carácter afectivo del vínculo establecido entre las empleadas domésticas y sus empleadores. El hecho de que tanto empleadores como trabajadoras hicieran depender sus derechos de relaciones que trascendían lo estrictamente laboral, así como el que recurrieran a distintos estereotipos de género en el marco de un proceso legal, obedece a la visibilidad que esos estereotipos habían ganado en el mundo público. En este sentido, si la sanción del decreto ley 326 y la creación del TTD pueden ser leídos como un avance de lo público sobre las relaciones establecidas en el servicio doméstico, las estrategias de trabajadoras y empleadores

\footnotetext{
${ }^{10}$ Idem.

11 Acta 337/1966.
} 
observadas en este período tensionarían este emplazamiento, mostrando la porosidad de los límites entre lo público y lo privado.

\section{Trabajadoras y empleadores frente al TTD en el cambio de siglo}

Al igual que en el escenario analizado anteriormente, para 2006, la mayor parte de quienes trabajaban en el servicio doméstico eran mujeres $(98,5 \%) .{ }^{12}$ Esta población contaba con un nivel educativo menor del que se constataba en el resto de los trabajadores, y en particular respecto de otras asalariadas. En este contexto, las trabajadoras domésticas se situaban entre los grupos con más bajos niveles de ingresos individuales. En lo que respecta a la situación laboral, según los datos oficiales, y en relación con el total del país, cerca del $72 \%$ de las ocupadas del servicio doméstico en 2009 trabajaba como externa para un solo empleador, aunque en la ciudad de Buenos Aires, en la mayoría de los casos, trabajaban para más de un empleador. Algunos de estos indicadores pudieron verse confirmados en el tipo de perfiles entre quienes reclamaban ante el TTD.

Respecto del momento anterior, la dinámica de los procesos iniciados entre fines de los años noventa e inicios de los 2000 presenta algunos cambios. Si anteriormente, los procesos se iniciaban con una denuncia espontánea de las trabajadoras ante las autoridades del TTD, para el cambio de siglo el proceso se iniciaba con una carta documento, lo que, en buena parte de los casos, implicaba la presencia de un abogado de la parte actora desde el comienzo del proceso. Esto se articula con una mayor relevancia del discurso legal en las estrategias desplegadas por las trabajadoras para fundar sus derechos. Desde mediados de la década de 1970, la referencia a dimensiones personales, familiares o morales en las demandas de las trabajadoras era mucho menos frecuente. La demanda y las subsiguientes contestaciones solían realizarse desde un discurso jurídico que no efectuaba consideraciones personales. Aún en los casos en donde los empleadores respondían con cuestiones que podrían injuriar o agraviar a las denunciantes, las trabajadoras no solían responder de la misma manera sino que encauzaban el conflicto hacia la lógica jurídica.

A diferencia de lo ocurrido anteriormente, en la mayor parte de las contestaciones, la parte demandada negaba la relación laboral, lo que en muchas veces, era, de hecho, tomado como una prueba de su ausencia. El punto de conflicto más importante, sin embargo, era la divergencia en cuanto al período trabajado y la dedicación horaria de la trabajadora. Para poder proseguir con sus demandas, las trabajadoras debían probar la existencia de un vínculo laboral de al menos cuatro días y cuatro horas semanales, condiciones necesarias para que su trabajo fuera amparado por el Estatuto del Servicio Doméstico. En las décadas transcurridas desde el horizonte temporal anterior, creció la proporción de trabajadoras empleadas por horas en detrimento de las internas.

${ }^{12}$ Todos los datos estadísticos presentados en este párrafo se basan en el informe "Caracterización del servicio doméstico en la Argentina", elaborado por la Subsecretaría de Programación Técnica y Estudios Laborales del MTEySS, 2006. 
Las pruebas de la existencia de la relación laboral provistas por las trabajadoras iban desde cartas de puño y letra, a listas de actividades a realizar por la empleada, cuadernos, listas de compras, fotos con sus empleadores, postales enviadas desde el extranjero, y la presentación de testigos. En relación a los testimonios, resulta importante señalar que, a diferencia de lo ocurrido anteriormente -cuando los cuestionarios resaltaban elementos personales en las disputas-, las preguntas estaban ahora orientadas a probar los elementos "objetivos" de la relación laboral (días y horas de trabajo, salarios estipulados, etc.).

La presentación de este tipo de pruebas, sin embargo, podía dar lugar a la reintroducción de consideraciones personales y a un lenguaje de afectividad. Las pruebas no solo buscaban probar la existencia de la relación laboral sino que también se usaban como una forma de evidenciar el nivel de confianza y la eficiencia de la trabajadora en sus labores. En un caso iniciado en 2004 por ejemplo, frente a la negación de la relación laboral por parte de los demandados, la trabajadora adjuntaba como prueba una postal que sus antiguos empleadores le enviaran a su propio domicilio durante un viaje a Roma. En la postal, los demandados la llamaban por su apodo, le pedían que cuidara a su hija y a su perro, y la saludaban de manera afectuosa, adelantándole que le llevarían un regalo al volver.

En otro expediente, iniciado en 1999, ante la negación de la relación de trabajo por parte de sus antiguos empleadores, la demandante presentó una serie de esquelas (hojas recortadas, invitaciones, tarjetas) en donde los empleadores realizaban diferentes pedidos y recomendaciones relativos a las tareas a ser realizadas. En una de estas notas, le solicitaban a la trabajadora que "aguant[ara] hasta fin de mes" para cobrar sueldo, mencionando explícitamente una dificultad laboral del empleador. El abogado de la empleada señalaba este último elemento como una evidencia de la "buena fe" y "disposición" que siempre mostró su defendida para trabajar aún sin recibir el salario en tiempo y forma. La presentación de este tipo de materiales podía dificultar la resolución del conflicto. Los empleadores tendían a considerar que su intimidad había sido violada, puesto que los elementos presentados como pruebas por las demandantes habían sido extraídos sin permiso de sus hogares, exponiendo su privacidad en un espacio público como el tribunal.

El uso de un discurso que remite al mundo privado por parte de las trabajadoras también es visible en otros casos, en particular en relaciones de trabajo más extensas, en las que las tareas de cuidado de niños o ancianos habían predominado sobre las de limpieza. Así, por ejemplo, en un expediente iniciado en 1998, una trabajadora que había cuidado de una pareja de ancianos por más de siete años demandaba a los hijos de sus antiguos empleadores, que para entonces habían fallecido. La trabajadora, que llamaba a la pareja "los abuelitos", y sostenía que los había querido como a miembros de su propia familia, señalaba que, a partir de la muerte de uno de los ancianos, los hijos de la pareja habían comenzado a exigirle que realizara tareas que no formaban parte del acuerdo inicial, abusando de la confianza y el amor incondicional que ella les profesaba, e intensificando su vigilancia sobre la trabajadora hasta un punto intolerable. La trabajadora sostenía incluso que la propia anciana le había dicho que sus hijos sólo querían quedarse con su casa y que nunca la habían acompañado tanto como la propia 
trabajadora. De este modo, la demandante justificaba sus derechos no sólo en la ley sino en una relación con sus antiguos empleadores que excedía por mucho lo estrictamente laboral.

La estrategia de las trabajadoras de fundar los derechos en el orden privado se sitúa en un escenario en el que el discurso de los derechos laborales había perdido legitimidad social. Las altas tasas de desempleo, el crecimiento del empleo informal y, en especial, la sanción de normas tendientes a la flexibilización de los derechos laborales vigentes hasta entonces hicieron que dicho lenguaje fuera una vía menos atractiva para expresar las demandas de las trabajadoras. En un contexto de re-privatización de las relaciones laborales, la apelación a moralidades en las que los derechos no dependen sólo de la ley y de las relaciones establecidas en el mundo público, sino de relaciones afectivas y cuasi familiares podía resultar más eficaz a los ojos de las trabajadoras.

Por otro lado, los empleadores frente al TTD seguían apelando a un lenguaje de afectividad de manera mucho más frecuente. Como en el horizonte anterior, los empleadores solían responder a las demandas de las trabajadoras buscando re-situar la relación laboral en el mundo privado, identificando a las trabajadoras como amigas o incluso como un miembro más de la familia, que con su demanda ponían en cuestión una relación que debía basarse en la gratitud y el afecto, y a la que muchas veces caracterizaban como "venganza". La persistencia de este tipo de respuestas da cuenta de que, a pesar de las cuatro décadas que habían pasado desde la sanción del decreto 326, en la mirada de los empleadores, aún era posible caracterizar las relaciones establecidas en el servicio doméstico como una relación de orden privado, en especial cuando se trataba de relaciones de varios años o en el caso de personas que habían trabajado como internas.

Así, por ejemplo, en un caso iniciado en 1999, el encuentro entre empleadores y empleada era tomado como un momento límite, en el que la trabajadora, caracterizada como una "niña desamparada", había sido salvada por una familia que la adoptó "como si" fuese una más de la familia. La trabajadora era presentada como una

chica que como muchos en nuestro querido país, a los trece años de edad, se la recibió, crió, cuidó y educó como una más de la familia cuando llegó del interior y porque su familia era muy humilde y tenía pocos recursos, siendo que se la acogió y crió como una más (...) Siempre fue una chica que buscaba más, mejorar y nosotros la quisimos ayudar siendo que era una persona que se la trataba como de la familia. ${ }^{13}$

Esta caracterización de la relación con la demandante buscaba desestimar sus reclamos. Al re-situarla en el mundo privado, los empleadores corrían el eje del conflicto, de los derechos laborales de la trabajadora, a una relación de reciprocidad fundada en elementos ajenos a la relación laboral. Así, de estar en falta (por no haber cumplido con sus obligaciones legales), los empleadores pasaban a ser acreedores de supuesta gratitud que la trabajadora les debería por haberla ayudado en un momento de necesidad.

\footnotetext{
${ }^{13}$ Acta 966/1999. Las cursivas son nuestras.
} 
En el cambio de siglo, la honorabilidad de las trabajadoras también sería puesta en cuestión en las defensas esgrimidas por los empleadores, sobre todo a partir de acusaciones de hurto. Si en las décadas previas dichas acusaciones también podían aparecer, eran mucho menos habituales. Este tipo de contestaciones no son ajenas al imaginario que desde los sectores medios se fue construyendo en torno a la "otredad" en un contexto en que sus condiciones de vida se pauperizaron (Guano, 2002). La cercanía física (con la expansión de las villas de emergencia en los años noventa) y simbólica (a partir de la pauperización de los sectores medios) había conformado una imagen en donde las personas de sectores populares podían competir y hasta cuestionar el status social de los empleadores. El hecho de que las trabajadoras, que simbólicamente garantizaban la identidad de clase media de los empleadores, al hacer un juicio, la ponían en duda (Kessler, 2004). Acusarlas de "ladronas" era un modo de canalizar las ansiedades generadas por dicha situación, restableciendo el orden puesto en cuestión.

Así, en 2006 una trabajadora doméstica iniciaba una demanda a sus antiguos empleadores, para los que había trabajado 17 años, y a los que reclamaba el pago de sueldos adeudados y horas trabajadas sin remuneración alguna durante más de cuatro años. En la contestación de la demanda, se puede entrever un relato que buscaba desviar la cuestión hacia un supuesto hurto que la trabajadora habría cometido, pero del que no se ofrecían pruebas. Dicha presentación era acompañada por una copia de un allanamiento policial realizado en la casa de la trabajadora, en el que se buscaban varios objetos de oro presuntamente extraídos del domicilio de los empleadores. Aunque el resultado de dicho allanamiento fue negativo, en el discurso de los empleadores, la propia presentación de la demanda y de las pruebas ofrecidas por la trabajadora eran prueba de su condición de "ladrona" y, a la postre, confirmaban sospechas que los empleadores decían haber tenido desde mucho antes del fin de la relación laboral. En particular, y más allá de los objetos de oro cuyo hurto no había sido probado, los empleadores acusaban a la trabajadora de haber hurtado el cuaderno de control de pagos, prueba fundamental en su demanda. Como en otros expedientes en los que intervenían acusaciones de hurto, en este caso no fue posible llegar a un acuerdo. La sentencia, finalmente, benefició a la empleada, aunque con un monto muy por debajo del solicitado inicialmente.

En términos generales, la acusación de robo operaba como una sombra que buscaba desprestigiar a quien realizaba la demanda. Esta narrativa enfatizaba la construcción de una lectura retrospectiva de los hechos que habían derivado en la presentación judicial de la empleada. Así, las presentaciones aparecían como una forma de reconstruir sospechas previas que se tenían respecto a las cualidades morales y éticas de la denunciante, apareciendo estratégicamente organizadas en el expediente. Al mismo tiempo, la acusación de hurto era una garantía para la no resolución del conflicto antes de la instancia de la sentencia. En tal sentido, es en estos casos es donde mejor se visualiza la capacidad que tenían los empleadores (y sus abogados) para descentrar el conflicto de un plano meramente jurídico y situarlo en una esfera de relaciones personales, obligaciones y lealtades incumplidas. 


\section{Consideraciones finales}

En este artículo exploramos los solapamientos de lo público y lo privado en las estrategias legales de empleadores y trabajadoras domésticas ante el TTD. La coexistencia de moralidades que apelaban a la ley u otras que anclaban los reclamos en el mundo de las relaciones afectivas y cuasi familiares es otra muestra de la porosidad de las fronteras que separan ambas esferas. En tal sentido, este trabajo hizo un esfuerzo por reponer la dimensión conectada de los mundos sociales al enlazar en el análisis de esferas y lógicas que podrían aparecer como desconectadas.

En este sentido, a partir de lo observado podemos señalar que en el marco de relaciones laborales originadas en el servicio doméstico, los empleadores veían las demandas de las trabajadoras como una afrenta que trascendía lo estrictamente laboral. Muchas veces presentaban las demandas de las trabajadoras como una acción que quebraba el vínculo afectivo construido durante la relación de trabajo, en base a la que podían establecerse arreglos informales difícilmente observables en otros tipos de empleo. La demanda judicial emplazaba la relación en el terreno de los derechos y del trabajo, en el mundo público, eliminando su ambigüedad. La respuesta de los empleadores buscaba resituar la relación en el orden privado, lo que les permitía cambiar el conflicto: de uno en el que estaban en falta por no haber cumplido con sus obligaciones legales como empleadores a uno en el que eran agraviados por las acciones de alguien a quien habían ayudado en un momento de necesidad y que quebraba con sus exigencias una relación basada en la reciprocidad y el afecto.

La continuidad de esta estrategia entre dos horizontes temporales separados por más de tres décadas muestra que, a pesar de la sanción de distintos derechos laborales para el sector, el servicio doméstico continuó estando en un lugar ambiguo entre lo privado y lo público y, más específicamente, entre el mundo familiar y el mundo laboral. Sin embargo, también encontramos diferencias en las estrategias de los empleadores entre ambos momentos. Aunque en los dos casos encontramos cuestionamientos a la moral de las trabajadoras, en el primer caso ellos estaban centrados en la moral sexual y en su adecuación a los roles de género dominantes, mientras en el segundo momento, se focalizaban en la posibilidad de presentar a la trabajadora como "ladrona". La recurrencia de la apelación a los estereotipos de género en los primeros años del TTD responde a la visibilidad pública que habían ganado en las décadas centrales del siglo, tanto entre los sectores medios (a los que pertenecían los empleadores) como entre los trabajadores. Por su parte, el proceso de pauperización y heterogeneización de la clase media que se iniciara en torno de los años ochenta y se profundizara en los noventa, se tradujo en nuevas ansiedades en torno de la pérdida de estatus. En ese marco, las acusaciones de hurto muestran las ansiedades generadas por el temor de perder el status conseguido.

El solapamiento entre lo público y lo privado no eran elementos exclusivos de las estrategias de los empleadores. Éstos eran también recurrentes en las de las trabajadoras, aunque no tuvieron la misma relevancia en los dos contextos analizados. Las transformaciones en el mundo del trabajo ocurridas durante el peronismo inspiraron nuevos posicionamientos de las trabajadoras domésticas que, con la sanción del primer régimen legal para el sector -después del golpe de 1955- se tradujeron en demandas 
de justicia. Sin embargo, el hecho de que los derechos de las mujeres, en particular los de las trabajadoras domésticas, fueran legitimados en discursos que hacían hincapié en sus vínculos con el hogar y la vida familiar explica que los reclamos de las trabajadoras también fueran muchas veces inspirados en una moralidad que hacía depender los derechos de relaciones establecidas en el orden privado.

Para el segundo momento analizado, en cambio, el discurso legal había ganado más espacio en las estrategias de las trabajadoras. Sin embargo, procedimientos como la introducción de pruebas materiales (notas, cartas, etc.) podían dar lugar a la reintroducción del orden privado en las demandas, dando lugar a consideraciones personales/morales de sí mismas y de sus empleadores. Por otra parte, en un escenario de re-privatización del trabajo, la caracterización de la relación con los antiguos empleadores como una relación de afecto o incluso similar a una familiar podía resultar atractiva para las trabajadoras.

Si el servicio doméstico ocupa un lugar ambiguo entre lo público y lo privado, esto es aún más visible en las estrategias ante las instituciones de justicia tanto de empleadores como trabajadoras. Su análisis nos permitió reflexionar sobre aspectos más amplios desde donde pensar la reconfiguración relacional de vínculos sociales en los que se ponen en juego la desigualdad, la intimidad y el trabajo remunerado. Este artículo finalmente buscó articular en el análisis contextos socio-históricos y aspectos analíticos de gran relevancia cuando se piensa en procesos de ampliación de derechos laborales en sociedades como la argentina.

\section{Bibliografía}

Anderson, B. (2000): Doing the Dirty Work? The Global Politics of Domestic Labor, London, Zed Books.

Bailly, F., F-X. Devetter, y F. Horn (2013): "Can working and employment conditions in the personal services sector be improved?", Cambridge Journal of Economics, 37 (2), pp. 299-321.

Birgin, H. (2009): "Sin acceso a la justicia: el caso de las trabajadoras domésticas en Argentina", en M. E. Valenzuela y C. Mora (eds.), Trabajo doméstico: un largo camino hacia el trabajo decente, Santiago, Oficina Internacional del Trabajo, pp. 261-284.

Blackett, A. (2011): "Introduction: Regulating Decent Work for Domestic Workers", Canadian Journal of Women and Law, 23, pp. 1-46.

Blofield, M. (2012): Care Work and Class: Domestic Workers'Struggle for Equal Rights in Latin America, Pennsylvania State University Press.

Boris, E. y J. Fish (2015): "Decent Work for Domestics: Feminist Organizing, Worker Empowerment, and the ILO", en D. Hoerder (ed.), Towards a Global History of Domestic and Caregiving Workers, Leiden/ Boston, Brill, 2015, pp. 530-552.

Canevaro, S. (2014):"Afectos, saberes y proximidades en la configuración de la gestión del cuidado de niños en el hogar. Empleadas y empleadoras del servicio doméstico en la Ciudad de Buenos Aires", Trabajo y Sociedad, 22, pp. 175-193. 
Chaney, E. y M. García Castro (eds.) (1989): Muchachas No More: Household Workers in Latin America and the Caribbean, Philadelphia, Temple University Press.

Cutuli, R. (2012): "Desigualdades en el acceso a la justicia: un "régimen de invisibilidad". El servicio doméstico en la provincia de Buenos Aires (1990-2010)", en Actas delPrimer Congreso Latinoamericano de Historia de las Mujeres, Buenos Aires.

Fescina, A. (1956): Régimen jurídico del servicio doméstico y su reglamentación, Tesis de Doctorado, Derecho y Ciencias Sociales, Buenos Aires: Universidad de Buenos Aires.

Goldstein, D. (2003): Laughter Out of Place. Race, Class, Violence, and Sexuality in a Rio Shantytown, Berkeley y Los Angeles, University of California Press.

Guano, E. (2002): "Spectacles of Modernity: Transnational Imagination and Local Hegemonies in Neoliberal Buenos Aires", Cultural Anthropology, 17 (2), pp. 181209.

Gutiérrez-Rodríguez, E. (2010): Migration, Domestic Work and Affect: A Decolonial Approach on Value and the Feminization of Labor, New York, Routledge.

Herzfeld, M. (1981): "Meaning and morality. A Semiotic approach to Evil Eye Accusations in a Greek Village", American Ethnologist, 8 (3), pp. 560-574.

Hondagneu-Sotelo, P. y E. Ávila (1997): “'I'm Here but I'm There': The Meanings of Latina transnational Motherhood", Gender and Society, 11 (5), pp. 548-571.

Hutchison, E. (2011): "Shifting Solidarities: The Politics of Household Workers in Cold War Chile", Hispanic American Historical Review, 91 (1), pp. 129-162.

Hutchison, E. (2006): Labores propias de su sexo: género, políticas y trabajo en Chile urbano 1900-1930, Santiago, LOM Ediciones.

James, D. y J. French (eds.) (1997): The Gendered Worlds of Latin American Women Workers, Durham and London, Duke University Press, 1997.

Kessler, G. (2004): "Inseguridad subjetiva: Nuevo campo de investigación y de políticas públicas", en A. Álvarez et al. (coords.), Estado, democracia y seguridad ciudadano. Apuntes para el debate, Buenos Aires, PNUD, pp. 107-142.

Lautier, B. (2003): "Las empleadas domésticas latinoamericanas y la sociología del trabajo: algunas observaciones acerca del caso brasileño", Revista Mexicana de Sociología, 65 (4), pp. 789-814.

Lobato, M. (2007): Historia de las Trabajadoras en la Argentina (1869-1960), Buenos Aires, Edhasa.

Lutz, H. (2008): Migration and Domestic Work: A European Perspective on a Global Time, Aldershot, Ashgate.

Mac William, E. (1999): Pedagogical pleasure, Nueva York, Peter Lang Publishing.

Milanesio, N. (2006): "The Guardian Angels of the Domestic Economy": Housewives' Responsible Consumption in Peronist Argentina", Journal of Women's History, 18 (3), pp. 91-117.

Milanich, N. (2011): "Women, Children, and the Social Organization of Domestic Labor in Chile", Hispanic American Historical Review, 91 (1), pp. 29-62. 
Nuño, L. (2008): La incorporación de las mujeres al espacio público y la ruptura parcial de la división sexual del trabajo: el tratamiento de la conciliación de la vida familiar y laboral y sus consecuencias en la desigualdad de género, Tesis de Doctorado, Universidad Complutense de Madrid.

Pateman, C. (1995): El contrato sexual, Barcelona, Anthropos.

Pérez, I. y S. Canevaro (2015): "Languages of affection and rationality: household workers' strategies before the Tribunal of Domestic Work (Buenos Aires, 19562013)", International Labor and Working-Class History, 88, pp. 130-149.

Pérez, I. (2015): "Un "régimen especial" para el servicio doméstico. Tensiones entre lo laboral y lo familiar en la regulación del servicio doméstico en la Argentina, 19261956", Cuadernos del IDES, 30, pp. 44-67.

Pite, R. (2011): “Entertaining Inequalities: Doña Petrona, Juanita Bordoy, and Domestic Work in Mid-Twentieth-Century Argentina", Hispanic American Historical Review, 91 (1),pp. 97-138.

PRECARIAS A LA DERIVA (2004): A la deriva por los circuitos de la precariedad femenina, Madrid, Traficantes de Sueños.

Rosenblatt, K. (2000): Gendered Compromises. Political Cultures and the State in Chile, 1920-1950, Chapell Hill, The University of North Carolina Press.

Salazar Parreñas, R. (2001): Servants and Globalization: Women, Migration and Domestic Work, Stanford, Stanford University Press.

Stagnaro, A. (2012): Los Tribunales del Trabajo como escenario del conflicto entre el capital y el trabajo. 1948-1960, Tesis del Doctorado en Historia, La Plata, Universidad Nacional de La Plata.

Suriano, J. (2007): "El largo camino a la ciudadanía social", en Susana Torrado (ed.), Población y bienestar en la Argentina del primero al segundo Centenario. Una Historia Social del siglo XX, Buenos Aires, Edhasa, Tomo II, pp. 69-96.

Tizziani, A. (2012): "Organización colectiva de las trabajadoras domésticas en la Ciudad de Buenos Aires: el impulso y sus límites", en Actas de lasVII Jornadas de Sociología- Instituto de Ciencias, Buenos Aires, UNGS.

Tomei, M. (2011):'Decent work for domestic workers: Reflections on recent approaches to tackle informality", Canadian Journal of Women and Law, 23 (1), pp. 185-212.

Valenzuela, M. E. y C. Mora (eds.) (2009): Trabajo doméstico: un largo camino hacia el trabajo decente, Santiago de Chile, Oficina Internacional del Trabajo.

Vázquez Lorda, L. (2010): "El otro ángel del hogar es mujer, trabajadora y asalariada. Las empleadas domésticas y el catolicismo en la Argentina de los años 1950", en N. Álvarez (comp.), Familia, género y después... Itinerarios entre lo público, lo privado y lo íntimo, Rosario, Prohistoria, pp. 107-126.

Vianna, A. (2010):"Derechos, moralidades y desigualdades: Consideraciones a partir de procesos de guarda de niños", en C. Villalta (ed.), Infancia, justicia y derechos humanos, Bernal, Universidad Nacional de Quilmes, pp. 21-72. 